\title{
Clio
}

Femmes, Genre, Histoire

$12 \mid 2000$

Le genre de la nation

\section{« Nou Le Pa Z'enfants batards » : la construction par la France du genre outre-mer}

\section{Arlette GAUTIER}

\section{(2) OpenEdition}

1 Journals

Édition électronique

URL : https://journals.openedition.org/clio/188

DOI : 10.4000/clio.188

ISSN : 1777-5299

Éditeur

Belin

Édition imprimée

Date de publication : 1 novembre 2000

ISBN : 2-85816-554-8

ISSN : $1252-7017$

\section{Référence électronique}

Arlette GAUTIER, « « Nou Le Pa Z'enfants batards » : la construction par la France du genre outre-

mer », Clio [En ligne], 12 | 2000, mis en ligne le 18 septembre 2008, consulté le 24 mars 2023. URL :

http://journals.openedition.org/clio/188 ; DOI : https://doi.org/10.4000/clio.188

Ce document a été généré automatiquement le 24 mars 2023.

Tous droits réservés 


\title{
« Nou Le Pa Z'enfants batards » : la construction par la France du genre outre-mer
}

\author{
Arlette GAUTIER
}

\section{RÉSUMÉS}

La France a toujours promu outre-mer une construction du genre fort différente de celle qui avait cours en métropole. Que ce soit pendant l'esclavage (1635-1848), pendant la période de la citoyenneté coloniale (1848-1938) ou bismarckienne (1938-1963), il n'y a pas eu de soutien au modèle de l'homme-pourvoyeur, sans qu'il y ait de prise en compte du maintien d'un modèle polygamique. Le passage de la parité sociale à l'égalité sociale reste inachevé pour les plus pauvres, et particulièrement pour les allocataires de parent isolé.

Gender in French overseas territories has always been constructed differently that in metropolitan France. Whether it be under slavery (1635-1848) or during the periods of colonial (1848-1938) or Bismarkian (1938-1963) citizenship, the European model of the male breadwinner was not applied nor was the continued existence of a polygamous model recognized. The passage from social parity to social equality is thus incomplete for the poorest members of society and notably for single-parent beneficiaries of family allowances. 


\section{AUTEUR}

\section{ARLETTE GAUTIER}

Arlette GAUTIER, maîtresse de conférences en démographie à l'Université de Paris X-Nanterre, a d'abord travaillé sur l'esclavage puis sur les politiques démographiques et familiales aux Antilles françaises et au Mexique, puis dans le monde. Elle approfondit actuellement la notion de droits reproductifs et coordonne, avec Myriam Cottias, l'enquête sur les violences faites aux femmes aux Antilles-Guyane, prolongement de l'enquête nationale dirigée par Maryse Jaspard. 